\title{
Did the 2019 One and Half-Month Boot Camp Training Enhance Rwanda Development Board (RDB) Interns' English Proficiency?
}

\author{
Gloriose Mugirase* and Speciose N. Ndimurugero
}

University of Rwanda, College of Arts and Social Sciences, Rwanda

\section{ARTICLE INFO}

Keywords:
Language-Learning
$\quad$ Impediment
Listening skills
Reading skills
Speaking skills
Writing skills

\begin{abstract}
Employers in Rwanda have been expressing their dissatisfaction with university graduates' low English proficiency affirming that it hindered their performance at work. Rwanda Development Board (RDB) also noticed that the English proficiency and work readiness skills of university graduates on internship in 2019 left a lot to be desired, which was an impediment to the completion of the internship and to the development of their professional skills. To enhance these graduates' communication and work readiness skills, the Rwandan Government, through RDB, sent them to a one and half-month employability boot camp at the University of Rwanda. Therefore, this study aimed at investigating factors that hindered these interns' development of English proficiency and at exploring whether the course helped improve their skills in this language. For the sake of validity and reliability, both qualitative and quantitative research paradigms were applied to collect and analyse the research data. Themes emerging from classroom observations and interviews were analysed inductively and figures used to interpret the trainees' results in the entry and exit English proficiency tests. Research findings revealed that unfavorable linguistic environment, teachers limited English proficiency, and regular shifts in the medium of instruction were major impediments to the trainees' improvement of English proficiency. Findings also disclosed that the training had helped the majority of participants boost the four language macro modalities, but that more time was required for slow learners. In agreement with the findings, some recommendations were made on how to effectively support Rwandan students' learning of English.
\end{abstract}

\section{Introduction}

Until recently, employers in Rwanda have voiced concerns about university graduates' low English proficiency maintaining that it hindered their performance at work. As Tanganyika (2018) states, the Rwandan generation of university graduates lack good English communication skills and employers have long complained that many of them are not fit for the job market. Rwanda Development Board (RDB), a government department whose mission is to fast-track the country's economic development, also noted that the English language proficiency and work readiness skills of university graduates on internship in 2019 left a lot to be desired. This gap constituted a serious impediment to the completion of the internship and to the development of their professional skills.

To enhance these graduates' communication and work readiness skills and enable them to compete in national, regional or international job market, the Government of Rwanda, through $\mathrm{RDB}$, sent them to a one and half-month employability boot camp at the University of Rwanda from the $20^{\text {th }}$ October to the $5^{\text {th }}$ of December, 2019. It is against this background that the

* Corresponding Author E-Mail Address: gmugirase@gmail.com 
researchers, after the RDB interns' agreement to become research participants, embarked on investigating factors that prevented them from developing competence in English, a language they were assumed to have been schooled through for years. The researchers also wanted to evaluate whether the one and half-month boot camp had contributed to the improvement of the interns' English proficiency and if similar boot camps were worth recommending. (As soft skills were taught by two outsiders, the present study focused on English communication skills only, the researchers' field of interest.)

The primary goal of the present study was, hence, to explore whether the one and half-month boot camp training organised for RDB interns helped to promote their English language proficiency. The secondary aims were to find out (1) how proficient in English the trainees were before the boot camp training started and after its completion, and (2) how their level of English proficiency before the training compared with their proficiency at the end of the training.

\section{Materials and Methods}

The choice of a research design is dependent on the research purpose. This study used a casestudy design as it aimed at deeply exploring a particular phenomenon in its real life and in its specific milieu (Ridder, 2017). Indeed, the researchers wanted to explore how the trainees responded to the training they were following in the boot camp as well as the impact this training had on their learning of English.

To collect and analyse data, the current study made use of both qualitative and quantitative research approaches for the sake of complementarity as each method has its strengths but also its weaknesses (Yeasmin \& Rahman, 2012). This allowed the researchers to gain more insight of the phenomenon under investigation. The qualitative research method enabled them to collect and analyse data from classroom observations and interviews (semi-structured). The interview questions were written in both English and Kinyarwanda to allow participants to respond in the language in which they felt more comfortable. Only eight participants opted for the English version while twenty-four chose to answer in Kinyarwanda. As for the quantitative approach, it facilitated the processing of the trainees' results. These were results from the English proficiency test they sat for at the beginning of the training and their results upon completion of the training.

Purposive sampling was utilised in the selection of participants. The boot camp consisted of about 300 RDB interns split into 12 groups, each of which comprised of around 25 students. However, the sample population in this research encompassed only the researchers' respective groups $(\mathrm{N}=32)$, being the ones who promptly volunteered to participate in the study.

\section{Results and Discussion}

Research findings shed light on factors that prevented the students from developing English proficiency before they followed the boot camp training and on the impact the course had on the development of this target language.

\subsection{Impediments to the Development of English Proficiency}

Research findings reveal a number of obstacles that restrained trainees from improving their English language proficiency before the boot camp training. However, this study will discuss only the major hindrances. These are an unfavorable linguistic environment, teachers limited English proficiency, and regular shifts in the medium of instruction.

The linguistic environment in which trainees lived was not conducive to the learning of English. According to Kagwesage (2013), English remains a foreign language in Rwanda despite the official status it enjoys. In the same vein, Sibomana (2014) asserts that Rwandans barely use English in their daily communication. While English is acquired as a foreign 
language, Kinyarwanda, the mother tongue, is spoken by more than $99 \%$ of the Rwandan population (Kagwesage, 2013; Mugirase, 2020; Ndimurugero, 2015; Samuelson \& Freedman, 2009; Sibomana, 2014). This suggests that the linguistic environment in Rwanda does not promote the learning of other languages since Rwandans can communicate effectively through using Kinyarwanda only.

Findings from this study show that 5 participants never had the opportunity to learn English, and that most of the others had had only very limited exposure to this language before joining the boot camp. Not surprisingly, all the trainees involved in the study failed the English language proficiency entry test and their marks ranged from $15 \%$ to $40.5 \%$. However, after a six-week boot camp training (from 21 October to 5 December), their exit test marks (ranging from $40.5 \%$ to $76 \%$ ) reveal that they all made good progress. According to these results, it can be implied that the trainees' English skills improved considerably. This is, thus, evidence that the research participants would have presumably developed more competence in English and coped with job language-related requirements if the English course had been given its due value and was allotted sufficient time during their school years. The challenge related to time complies with Ndimurugero (2015)' view that English courses are scarcely allocated enough time and that even the few hours they are allotted are available at the wrong time in learners' educational development. Given enough time, learners would engage in active interactions with peers and with teachers either orally or in writing, thus developing communication skills they need to meet job requirements.

Results from classroom observations also emphasise this assumption that the trainees could have developed their English proficiency if their learning had been fully supported. Indeed, they were motivated to learn, had an inquisitive mind, and were eager to perform different various learning activities provided them. The trainees' thirst to learn was, however, exacerbated by the belief that the improvement of their English would offer them more chance to secure job opportunities. They associated their learning with the RDB set goals: acquiring communication skills required from job seekers. Thus, their motivation to learn was instrumental in that most trainees expected RBD to help them in getting jobs. According to $\mathrm{Du}$ (2009), instrumental motivation is the learning of a language for immediate practical goals such as passing some examinations, getting a job, social mobility and promotion.

Another sensitive issue concerns teachers' limited competence in the English language, a big hindrance to learning since we can only give what we possess. Research has widely shown that many Rwandan teachers' level of English proficiency is low to the extent that they transmit mistakes to their learners (Mironko, 2013; Ndimurugero, 2015; Niyibizi, 2015; Sibomana, 2014). According to Niyibizi (2015), Rwandan urban and rural lower primary school teachers are considered to be highly proficient in Kinyarwanda and to have unbalanced proficiency in English, which might negatively impact on students' learning. For instance, in secondary school, students' proficiency in English is limited to the extent that it restrains them from attaining good academic achievement (Mugirase, 2020; Uwambayinema, 2013). According to Uwambayinema, $34 \%$ of secondary school teachers have to teach all subjects through English when they have little or no understanding of that language. He is of the view that it would even be worthless to organise in-service training in English for them because of lack of basic knowledge in the language upon which the training would build. More effort should, hence, normally be made at the grassroots to help learners easily acquire the foreign language at an early age. If not, learners will suffer from their teachers' low proficiency in the English language (Jiang, 2014).

Findings also indicate that regular shifts in the medium of instruction hindered the research participants' development of English proficiency during the span of their studies. Pinon and Haydon (2010, p. 7) posit, for example, that Rwanda's adoption of the English medium of instruction would "increase a pool of citizens with at least a rudimentary level of English in 
coming years." Unfortunately, this is what has been happening on the ground. These constant switches in the language of instruction have negatively affected the quality of education in Rwanda (Mugirase, 2020; Ndimurugero, 2015), and both teachers and students are the ones to suffer the consequences of these unstable policies (Uwambayinema, 2013). These inconsistencies in the language-in-education-policy have made the mastery of English the most daunting challenge the Rwandan post-genocide government has ever had (Laviolette, 2012). If the sole English medium had been introduced in schools as an ongoing process, probably teachers and students would not be facing such language-related challenges nowadays.

\subsection{The 2019 Boot Camp Training and Enhancement of Trainees' English Proficiency}

This study also sought to determine whether the 2019 RDB boot camp training had enabled the trainees to improve the four language macro modalities. Research findings indicate that the course allowed the participants to develop their English proficiency. Data emerging from the interviews show that all trainees, but one, felt that the English course taken in the book camp helped enhance their English proficiency. Moreover, exam results, as presented in Figure 1 below, also show that the participants made considerable improvements. Two students (S4 and S5)' marks were not considered, however, because they were not complete. S4 was shifted to another group towards the end of the training so his marks in the exit test could not be found whereas S5 missed his entry test (only their responses from interviews were taken into account). Therefore, it is only 30 participants' scores that are examined in this paper.

The marks were initially out of 100 but were converted out of 10 for the sake of presentation.

Entry and exit test marks

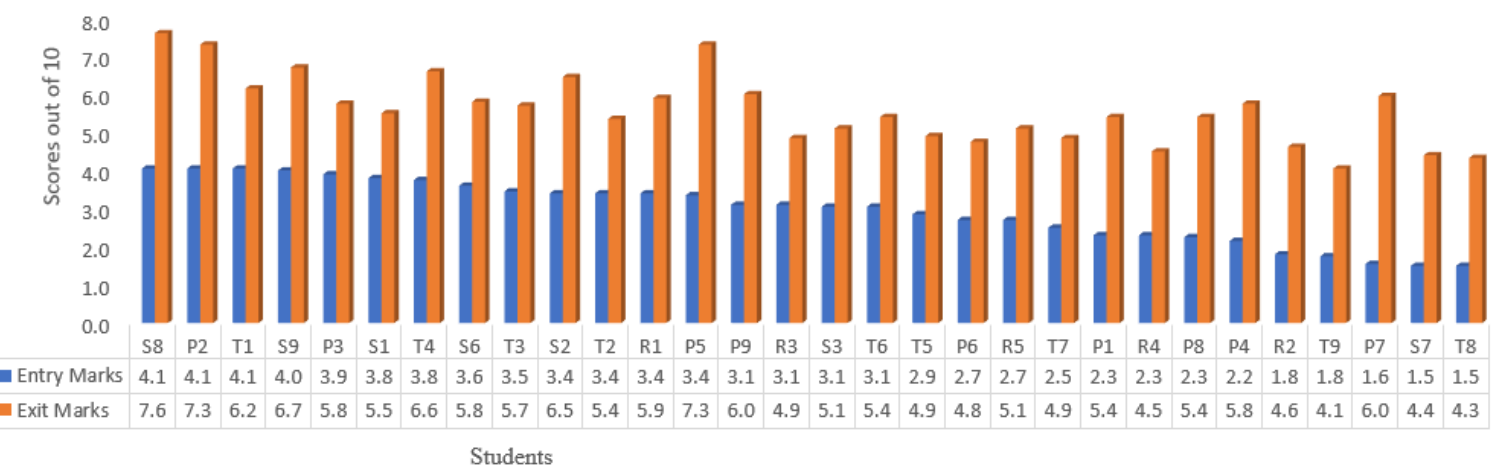

Figure 1. Students' Entry and Exit Test Results

The graph demonstrates that all students improved their English skills as they fared much better in the exist test than in the entry test. Even S7 who confessed not having benefitted a lot from the training gained somehow. She did not pass any of the two tests, but she scored $44 \%$ in the final exam whereas she had obtained $15 \%$ in the entry test.

The section below provides detailed information on the students' enhancement of the four English language skills (listening, speaking, reading, and writing) after completion of the training.

\subsection{Enhancement of Listening Skills}

Listening is a vital language skill that enables learners to acquire input and develop the other language skills (Zur, 2020). However, Tran \& Duong (2020) contend that lots of practices are required to acquire proficiency in this skill. Results from interviews reveal that 28 out of 32 participants were confident that their listening skills had improved. Their claim also matches findings from classroom observations. The researchers noted that listening appeared to be difficult at the very beginning of the training, but trainees gradually got accustomed and 
actively participated in activities during listening sessions. The trainees' assertion is also substantiated by their marks as displayed in Figure 2.

Marks in entry and exit listening tests

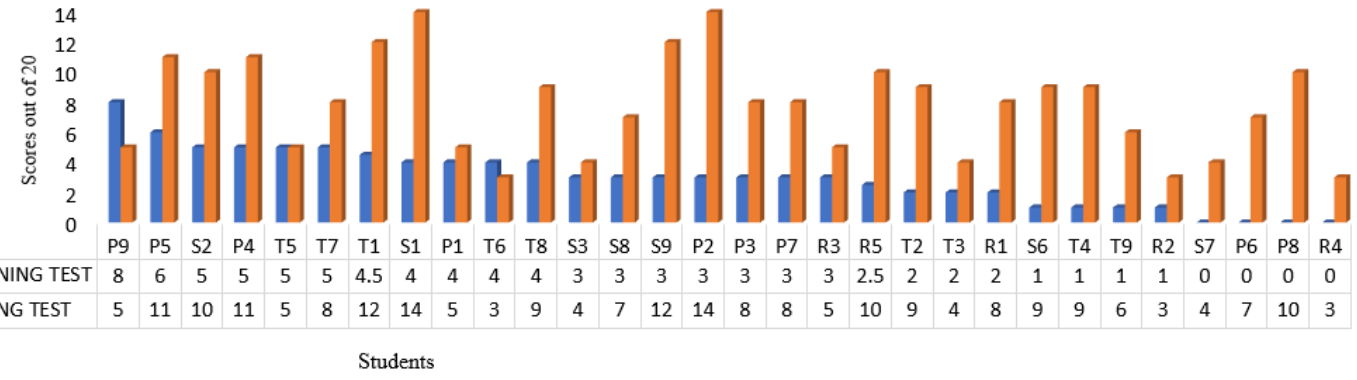

Figure 2. Students' Results in the Entry and Exit Listening Tests

The graph above shows that many students $(\mathrm{N}=27)$ did better in the exit test than in the entry test in listening. Only 3 students did not develop their listening skills. P9 obtained less marks in the exit test ( 5 out 20 ) than in the entry test ( 8 out of 20 ); T5 got the same scores in both exams ( 5 out of 20), and T6 had 4 and 3 out of 20 . These three students' results indicate that they needed much more support to increase their listening skills in English, and this would have been possible only if the course had been allotted much more time. Furthermore, even though the other trainees' marks ameliorated, 18 of them still did not have half of the marks in the exit test. They also needed more assistance to boost their listening proficiency.

\subsection{Enhancement of Speaking Skills}

Results from interviews show that regular speaking practice and interactions with classmates helped half of the participants $(\mathrm{N}=16)$ improve their speaking skills. This appears to be a great accomplishment since English speaking skills are regarded as the most essential skills that can enable EFL trainees "to enhance their career, build confidence levels, get better job opportunities, make public speeches, attend interviews, participate in debates and group discussions, give presentations..." (Rao, 2019, p. 9). In a similar vein, Leong and Ahmadi (2017) maintain that English speaking skills open doors to white collar jobs and to promotion. With regard to building confidence, the results indicate that the training helped another half of the trainees $(\mathrm{N}=15)$ to overcome their shyness and fear of public speaking, and to become selfconfident. However, findings from classroom observations disclose that only few trainees were involved in individual speaking activities and that the majority preferred group discussions. Four trainees confessed not having gained much from speaking sessions but admitted to having learnt how to pronounce words they used to mispronounce before they took the course.

The researchers also observed that, despite the teachers' endeavour to mediate the learning, the students' utterances were marked by grammatical inaccuracies, limited English vocabulary, lack of fluency and word mispronunciation. Teachers did their best to boost the trainees' English speaking skills through a variety of interactive activities. Activities such as pair or group classroom discussions, individual and group presentations, debates, storytelling, snowball throwing and jigsaw puzzle for speaking were conducted. This complies with Rao's view that, in the modern world, teachers should meet their students' communication needs in accordance with real-life and employability communication demands.

Findings also reveal that most of the trainees improved their speaking skills because they had better marks in the exit than in the entry test (see Figure 3).

However, information related to P7 results is not recorded because he missed the entry test. 


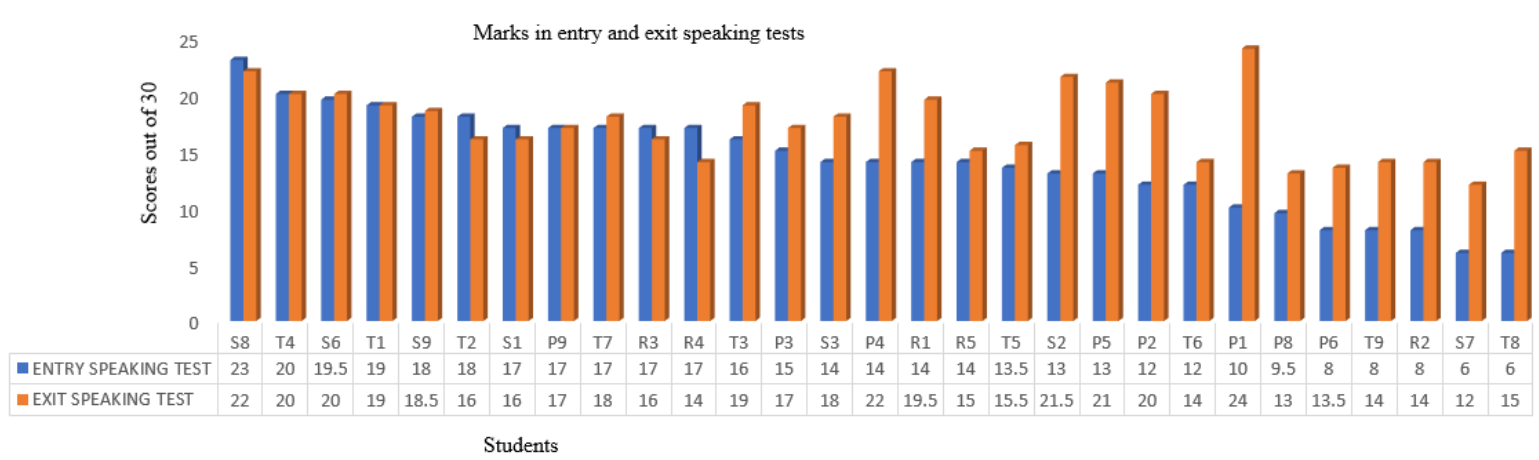

Figure 3. Students' Results in Entry and Exit Speaking Tests

From the graph above, it can be noticed that 20 out 29 students succeeded better in the entry than in the exit test although some of them $(\mathrm{N}=6)$ still failed. The graph also shows that 3 trainees scored lower marks in the exit test, and 2 others had the same marks in both exams. Although there are trainees who did well in the course, the research findings disclose that all would have benefitted from a longer training to boost their speaking proficiency.

\subsection{Enhancement of reading skills}

Results from interviews specify that the majority of participants recognized having improved their reading skills thanks to lots of reading practice. Their claims agree with results from classroom observations. During classroom observations, the researchers noted that students had either questions to answer or gap texts to fill in while listening to videos before or after the reading itself and during the writing session. Reading gapped texts generally happened prior to writing and writing exercises widely consisted of jumbled texts that students had to read carefully, understand and put in the right order. Thus, reading happened in all sessions. The teaching methodology also helped trainees develop their reading skills. Trainers incorporated extensive reading into their lessons. Rather than lecturing during reading classes, teachers gave the trainees exposure to a series of meaningful texts such as letters, memorandums, reports, newspaper articles, to cite but a few, to equip them with communication and employability skills.

In relation to the above, Mugirase (2020) argues that students must be provided sufficient practice within each lesson and across lessons. Obviously, a lot of time was devoted to reading activities. This factor was very important because people who read a lot tend to become competent readers (Locher \& Pfost, 2020). All these factors imply that EFL/ESL learners with an intrinsic motivation to read can satisfactorily develop their reading skills and might not need additional training after they graduate. Even though the Rwandan linguistic environment appears not to be conducive to the learning of English, personal motivation to reading can contribute a lot to the enhancement of individual students' reading skills. According to Becker, McElvany and Kortenbruck (2010), there is a bidirectional relationship between reading motivation and reading literacy. Not only does students' engagement in significant reading improve their reading skills, but it also promotes their critical thinking and writing skills (Sackris, 2020). The trainees involved in the current study put efforts into reading as they expected to be offered jobs after completion of the training.

Data emerging from document analysis sustains the affirmation of many $(\mathrm{N}=25)$ of the trainees that their reading proficiency had developed. This is shown in Figure 4. below. 


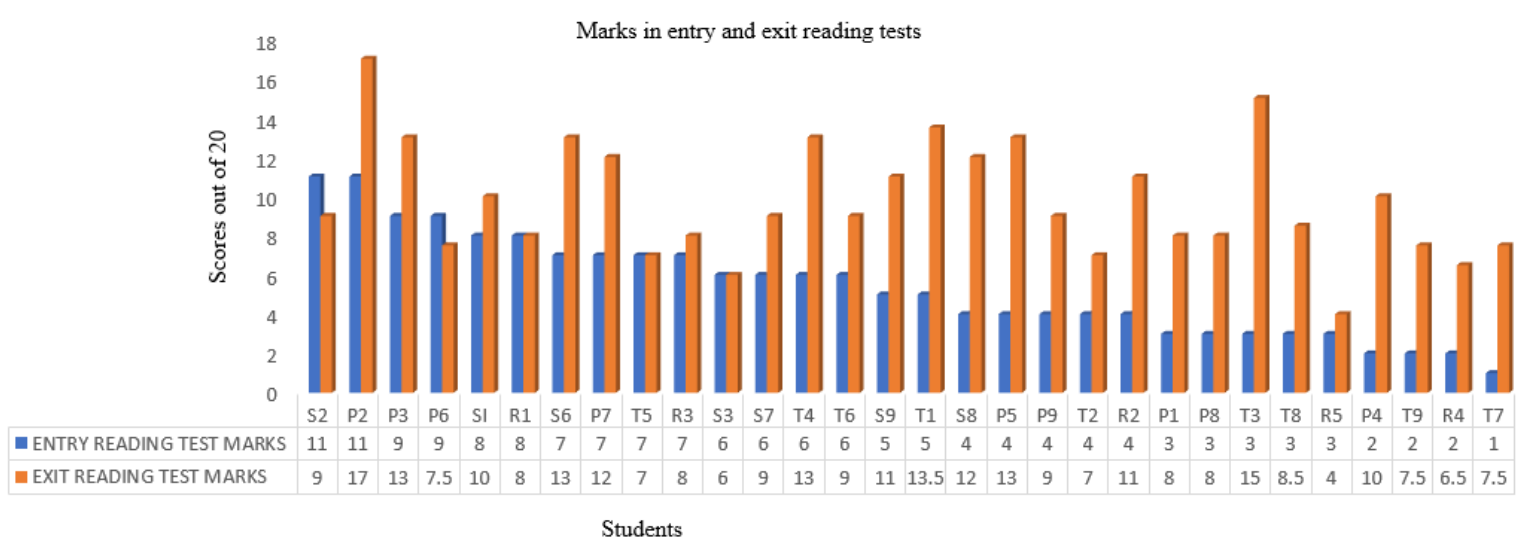

Figure 4. Students' Results in Entry and Exit Reading Tests

This graph indicates that among the 25 participants whose marks improved, only 13 passed the exit test while 12 failed. 2 students did badly in the entry exam and worse in the exit one. Other 3 participants obtained the same marks, that is, less than the pass mark.

Despite some trainees' improvement, these findings suggest that most of them needed more training to promote their reading skills in English.

\subsection{Enhancement of writing skills}

According to findings from interviews, 28 participants declared that regular writing practice they had during the training promoted their writing skills. Some explained that they could write good paragraphs, essays, letters, reports, memos, or to take meeting minutes.

Nevertheless, 4 participants admitted that they still had difficulties in writing either because of limited vocabulary or because they needed more time. In an EFL context, this sounds normal since writing is regarded as the most complex skill (Haerazi \& Irawan, 2019; Haerazi, Irawan, Suadiyatno, \& Hidayatullah, 2020; Javed, 2013; Tangpermpoon, 2008; Yulianti, Nuraeni, \& Parmawati, 2019; Tuan, 2010). According to Javed, writing is a very challenging skill even for English native speakers because students get exposure to the written form at school level only. In EFL context, it becomes more challenging as learners need to be acquainted with a number of factors such as the rhetorical organisations, appropriate language use, specific lexicon with which they want to communicate to the reader (Tangpermpoon, 2008), comprehension, sentence making/syntax, and tenses/grammar (Javed, 2013).

The researchers also consider that the six-week training as a whole was too short to help slow learners to develop their writing skill, especially that this skill was allotted only two hours per day. According to Haerazi and Irawan (2019), writing is a time-consuming unnatural action of learning in that learners have to recognise grammatical systems, patterns, and rules while reading. Results from classroom observations showed that there was no room for practice even though, in theory, trainees had to produce their own texts.

However, in the same way as for the other language skills, trainees scored better marks in the exit test than in the entry test, which is evidence that the course contributed to developing their writing proficiency in English (see Figure 5). 


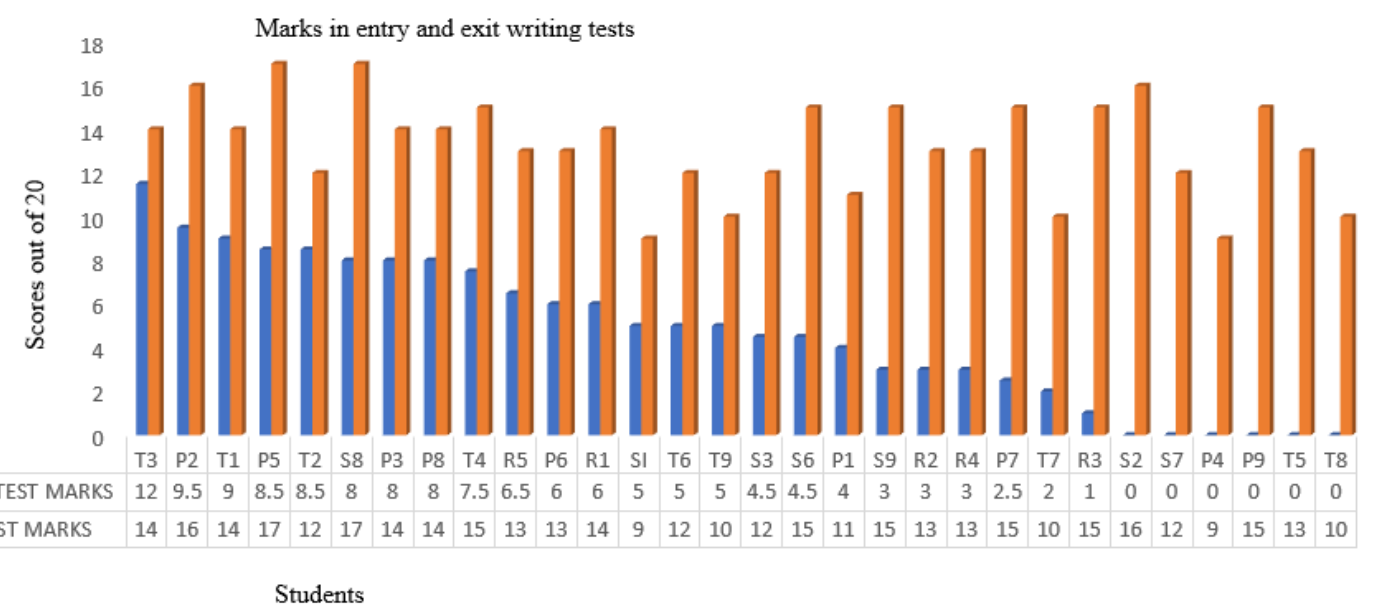

Figure 5. Students' Results in Entry and Exit Writing Tests

The graph above shows that the students did much better in the exit than in the entry test. In fact, only 2 trainees succeeded in the entry test whereas 28 passed the final exam. The latter's marks range between 10 and 17 out 20 . The findings also indicate that the trainees fared better in the exit writing test than in the other skills. The average mark out of 20 is 7.8 in listening, 11.5 in speaking, 9.8 in reading and 13.7 in writing. Nevertheless, as for the other skills, more time was indispensable to allow the trainees, especially slow learners, to develop skills in different written genres.

\section{Conclusions and Recommendations}

Findings from classroom observations, interview questions, and document analysis indicate that various factors had contributed to hindering the trainees' English language skills. The main factors that were identified are the linguistic environment that was not conducive to learning, teachers' lack of English proficiency, and regular shifts in the language of instruction. The findings also show that the boot camp training allowed most of the trainees to develop their English skills. Despite this, however, it cannot be claimed that they had become proficient enough to successfully apply for jobs, pass employment tests, or manage to communicate in English at work effectively. They still had a long way to go. If the training had lasted longer, these trainees would have possibly acquired competence in English.

From these findings, some recommendations need to be made to contribute to the field of research. Firstly, the Rwandan government should organise boot camp trainings for Rwandan university graduates who suffer from lack of English language proficiency to enable them to develop skills in this language whose mastery has become vital for effective communication in Rwanda and all over the world. Implementing this project would be obviously costly, but it would be even costlier for the country to have many graduates incapable of competing in the job market because of low skills in English. Secondly, as the Rwandan environment is not favourable to the learning of English, this target language should be taught at all school levels and allotted sufficient time to allow students to be more acquainted with it. Thirdly, the government should appoint English teachers who are proficient in this medium of instruction so that they can effectively mediate their students' learning. Fourthly, Rwandan universities should introduce an intensive English course in their first years' English programmes to allow all freshmen to acquire enough English input, be active in the learning process, become confident, and develop English proficiency required by job seekers. Lastly, the language-ineducation policy should be elaborated in such a way that regular shifts in the medium of instruction are avoided. 


\section{References}

Becker, M., McElvany, N., \& Kortenbruck, M. (2010). Intrinsic and extrinsic reading motivation as predictors of reading literacy: A longitudinal study. Journal of Educational Psychology, 102(4), 773.

Du, X. (2009). The affective filter in second language teaching. Asian Social Science, 5(8), $162-165$.

Haerazi, H., \& Irawan, L. A. (2019). Practicing genre-based language teaching model to improve students' achievement of writing skills. IJELTAL (Indonesian Journal of English Language Teaching and Applied Linguistics), 4(1), 9-18.

Haerazi, H., Irawan, L. A., Suadiyatno, T., \& Hidayatullah, H. (2020). Triggering preservice teachers' writing skills through genre-based instructional model viewed from creativity. International Journal of Evaluation and Research in Education, 9(1), 234-244.

Jiang, X. (2014). Chinese biology teaching assistants' perception of their English proficiency: An exploratory case study. The Qualitative Report, 19(42), 1-24.

Kagwesage, A. M. (2013). Coping with English as language of instruction in higher education in Rwanda. International Journal of Higher Education, 2(2), 1-12.

Laviolette, G. (2012). English language acquisition and mastery: Rwanda's urgent economic need. Delta Kappa Gamma Bulletin, 79(1), 43-49.

Leong, L. M., \& Ahmadi, S. M. (2017). An analysis of factors influencing learners' English speaking skill. International Journal of Research in English Education, 2(1), 34-41.

Locher, F., \& Pfost, M. (2020). The relation between time spent reading and reading comprehension throughout the life course. Journal of Research in Reading, 43(1), 57-77.

Mironko, B. K. U. (2013). Students and teachers' views on factors that hinder or facilitate science students in mastering English for academic purposes (EAP) in Rwanda higher education. Doctoral thesis. Cape Town: University of the Western Cape.

Mugirase, G. (2020). Language of instruction and quality of education in Rwanda: A case study of secondary school third form learners in the Gisagara District. Doctoral thesis. Cape Town: University of the Western cape.

Ndimurugero, N. S. (2015). Learning English for academic purposes in higher education in Rwanda: A case of the College of Business and Economics. Doctoral thesis. Cape Town: University of the Western Cape.

Niyibizi, E. (2015). The Rwandan teachers' and learners' perceived speaking proficiency in both Kinyarwanda and English after 2008-2011 consecutive language-in-education policy shifts. Rwandan Journal of Education, 3(1), 91-116.

Pinon, R., \& Haydon, J. (2010). The benefits of the English language for individuals and societies: Qualitative indicators from Cameroon, Nigeria, Rwanda, Bangladesh, and Pakistan. London: The British Council \& Euromonitor International.

Rao, P. S. (2019). The importance of speaking skills in English classrooms. Alford Council of International English \& Literature Journal (ACIELJ), 2(2), 6-18.

Ridder, H. G. (2017). The theory contribution of case study research designs. Business Research, 10 (2), 281-305.

Sackris, D. (2020). How to encourage reading and learning in the college classroom? Teaching Philosophy. 
Samuelson, B.L., \& Freedman, S.W. (2010). Language policy, multilingual education, and power in Rwanda. Language Policy, 9(3), 191-215.

Sibomana, E. (2014). The acquisition of English as a second language in Rwanda: Challenges and promises. Rwandan Journal of Education, 2(2), 19-30.

Tanganyika, F. (2018). Proficiency in English by college graduates is tenable. The New Times.

Tangpermpoon, T. (2008). Integrated approaches to improve students writing skills for English major students. ABAC journal, 28(2).

Tran, T. Q., \& Duong, T. M. (2020). Insights into listening comprehension problems: A Case study in Vietnam. PASAA: Journal of Language Teaching and Learning in Thailand, 59, $77-100$

Tuan, L. T. (2010). Enhancing EFL learners' writing skill via journal writing. English Language Teaching, 3(3), 81-88.

Uwambayinema, E. (2013). Science teachers' challenges implementing Rwanda's English as a medium of instruction policy: a case study of Nyarugenge district rural secondary schools. Master's dissertation. College of Arts and Humanities, California State University, Fresno.

Yeasmin, S., \& Rahman, K. F. (2012). Triangulation research method as the tool of social science research. BUP journal, 1(1), 154-163.

Yulianti, S., Nuraeni, S., \& Parmawati, A. (2019). Improving students' writing skill using brains writing strategy. Project (Professional Journal of English Education), 2(5), 714-721.

Zur, S. (2020). EFL Students' English listening comprehension problem: A study of English teacher education program. Advances in Social Sciences Research Journal, 7(1), 268-273. 